\title{
Features of the development of human capital in Kemerovo mining region
}

\author{
Tatiana Snegireva ${ }^{1, *}$, Aleksei Ezhov $^{2}$, Svetlana Kostyuk ${ }^{3}$, and Michal Cehlar ${ }^{4}$ \\ ${ }^{1}$ Russian State Library, International Education Cooperation Sector, 119019 Vozdvizhenka st., 3/5, \\ Moscow, Russian Federation. \\ ${ }^{2}$ Plekhanov Russian University of Economics, Academic Department of Organizational and Managerial \\ Innovation, 115093 Stremyanny sidestreet, 36, Moscow \\ ${ }^{3}$ T.F. Gorbachev Kuzbass State Technical University, Vice Rector for Research and International \\ Cooperation, 650000 Kemerovo, Vesennya st., 28 Russian Federation \\ ${ }^{4}$ Technical University Košice, Faculty BERG, Letná 9, 04001 Košice, Slovakia
}

\begin{abstract}
Significant impact on the formation and use of human capital are exerted by factors and conditions that correspond to the levels of government and form continuously interconnected and warring groups. Combined socioeconomic category "human capital" was formed as a result of notable changes in the human as the main productive force and socio-economic subject of society. Practice shows that regions with significant human capital are in a better position compared to competitors that do not have similar advantages. Targeted projects of the formation and use of human regional capital such as the international acceleration program "Russian-Chinese Youth Business Incubator" allows not only effectively form and use the human capital of the region, but also increase its competitiveness.
\end{abstract}

\section{Introduction}

At the present stage of development of our country, the main element of social reproduction and a decisive factor in economic growth and ensuring the well-being of the population on this basis is human capital and its effective use. The combined socio-economic category of "human capital" was formed as a result of marked changes in man himself as the main productive force and socio-economic subject of society.

One of the first formulations of the concept of "human capital" was proposed by the English economist W. Petit. He introduced the category of "living acting forces", which generalized and combined the various properties and abilities of a person participating in the process of social production. William Petty made an attempt to assess the monetary value of the productive qualities of the human person, and also proposed a method for calculating the value of each person and the losses that a country has from loss of life during the war, epidemics, from exiling them abroad, to serve other states [6].

The problem of reproduction and improving the quality of human capital is becoming extremely urgent at all levels of government: global, state, regional and municipal. At the

* Corresponding author: snegireva_tv@mail.ru 
level of individual constituent entities of the Russian Federation, the level of development of human capital is still extremely rarely taken into account when forming a regional social and economic policies. At the same time, investments in education and healthcare create "human capital" in the same way as the costs of equipment and materials create physical capital. The growth of the mental and physical abilities of the employee as components of human capital is compared with the accumulation of material and material elements of production. Human capital "increases the economic ability of people for a long time."

In our opinion, a well-thought-out policy of the formation and use of human capital will allow us to link the totality of interconnected and interacting processes taking place at the federal, regional and municipal levels of government. Today it becomes obvious that the development of Russia, its regions, municipalities is directly dependent on the formation of a policy of using human capital as a complexly structured, but holistic and balanced unified state policy [10].

\section{Materials and Methods}

Factors and conditions for the formation and implementation of the policy of using human capital as a form of human capital management are manifested at all levels of government. However, the set of these factors and conditions at each level of government is different in types and depth of manifestation. It is this circumstance that requires objective consideration in the process of formation, formation and practical implementation of the policy of using human capital in order to ensure the unity of the managerial space, based on the specifics and characteristics of the development of socio-economic systems of different levels that have developed historically under the influence of factors and the formed conditions for their implementation in the past historical periods of development of socio-economic systems.

The methodological, theoretical and practical basis for the formation of a single managerial space is integrated policy as a form of human capital management. It is it that is the foundation for smoothing out all inter-level contradictions, creating the prerequisites for the implementation of the totality of factors as a driving force and resource in neutralizing the totality of conditions that impede their implementation, and finally, creating a single managerial space in the socio-economic system of the Russian Federation [8].

In this policy, the "linking" of factors, conditions and mechanisms of inter-level interaction of subjects of management should be implemented, creating the basis for the practical formation of a single managerial space. This logically involves the consistent identification of all factors, conditions and characteristics of their relationship and interaction. This approach allows, on the one hand, to identify the internal reserves (conditions) of the policy of using human capital, and on the other, to assess the sufficiency of factors to neutralize the negative conditions for the implementation of the policy of using human capital in the socio-economic system. Given the characteristics of each region, municipality - geographical, economic, political, socio-demographic, historical and other factors and conditions for the formation and development of policies for the use of human capital, can vary in its fullness, thereby reflecting the specifics of each territory.

In general, the interaction of factors initiating the formation of a policy of using human capital, their effectiveness in counteracting negative conditions that impede the formation of a new institutional and innovative environment, makes it possible to open up internal reserves. The use of these resources creates the basis for the transition of the socio-economic system to the path of innovative development.

The political factors initiating the implementation of the policy of using human capital of an innovative type include:

- objective coordinated management actions of executive and representative bodies of power at all levels. The implementation of this factor is the initial basis for the formation of a single 
managerial space, creating fundamentally new conditions for the balanced socio-economic development of the Russian Federation at the macro, meso and micro levels, the formation of a single managerial space;

- taking into account the peculiarities of the regions in the formation and implementation of the integral personnel policy of the state, taking into account the characteristics and specifics of the regions, low competitiveness of managerial personnel, the absence of mechanisms for interaction of state government entities at all levels in the implementation of a single personnel policy [9].

Braking opposition to the implementation of this group of factors is exerted by the following conditions. This is, first of all, the low level of legal support for the interaction of the state, regions and municipalities, as well as the low quality of management and the gap in the common managerial space, the autonomy of the personnel policy at the macro, meso and micro levels, the lack of consideration of the peculiarities of regions in its implementation, political crises, military conflicts, inconsistency of interaction between the actors of a multi-level system in the implementation of the policy of using human capital.

Economic factors include: a high level of competitiveness of human capital, effective stimulation of labor productivity and the use of resources, an optimal and balanced structure of regional production and a high level of diversification, leading and systemic innovative development of production, institutional support for innovative development, effective state regulation of economic processes on macro, meso and micro levels, stimulating economic growth and state tax and addressable oriented innovation policy state, stable and balanced growth, an optimum inter-branch structure, the active and advanced institutional policies [4].

The conditions that counteract the implementation of this group of factors include: a low level of training and retraining of personnel, which does not provide an increase in their competitiveness, weak and unsystematic stimulation of labor, the mono-directional economy of the region, the institutional lag of innovative transformations, personnel imbalance of the socio-economic system, cyclical economic development, weak regulation and stimulation of economic processes, imperfection of the tax policy of the state, lower growth, wear and tear, the lag institutional changes, braking and immunity innovative development [10].

Social factors include targeted priorities of active and passive social policies, effective social protection, continuous accumulation of intellectual capital: knowledge, skills, competencies, rational structure of human capital, improving the quality of life of the population, the formation of a healthy lifestyle, qualitative and balanced structure population regulated by migration processes, a reasonable migration policy, increasing the life expectancy of the population and able-bodied five people, and highly competitive level of the population, the state regulation of the social processes of the state policy in the sphere of environmental protection, promotion of the birth rate, mortality reduction [4].

The opposing conditions for the implementation of these factors are: poor use of active forms of social policy, low level of accumulation of human capital, over-accumulation of obsolete knowledge, skills, and lack of approaches to their denial, the presence of environmentally hazardous and harmful industries, the accumulation of large volumes of industrial solid waste, deviant lifestyle of a significant part of the population, unbalanced population structure, negative balance of fertility and mortality, poorly regulated migration policy, low competitiveness of the population, the presence of more than $50 \%$ of the population, close in terms of living to the minimum subsistence level, vertical and horizontal inconsistency of regional actions in the implementation of personnel policy, its autonomy, the predominance of passive forms of social policy, steady dynamics of population aging and reduction able-bodied population [8].

Of course, the action of factors and the neutralization of opposing conditions requires not only the development and implementation of a policy of using multilevel-type human capital, 
but also the justification of the integrated mechanism that ensures their interaction and includes regulatory, organizational and other targeted mechanisms.

\section{Results and Discussion}

Consider an example of a policy of using human capital in a region using the example of the Kemerovo region.

Kemerovo region is a unique coal basin, within the boundaries of which there are deposits of various brands: coking coal, high-quality steam coal. The region in terms of population takes 3rd place among 10 regions of the Siberian Federal District. The region is the leader in the Russian Federation in the number of single-industry municipalities - 24 single-industry towns, 4 of which are territories of socio-economic development. Kuzbass has the highest percentage of urbanization $-84 \%$ of the urban population, while $1 / 3$ of the economically active population has a higher professional education. On the territory of the region there are 7 higher educational institutions in which 48.1 thousand people are studying.

One of the key universities that train personnel and take an active part in the formation of human capital for the region for 70 years is the Kuzbass State Technical University.

One of the effective innovative projects for the formation of human capital in the region, implemented on the basis of the Kuzbass State Technical University over the past few years, is the international project Russian-Chinese Youth Business Incubator.

The international acceleration program "Russian-Chinese Youth Business Incubator" (hereinafter referred to as the project) is an international project to unite the active youth of Russia and China, the founders of innovative start-ups based on advanced achievements of science and technology. For the first time, the Business Incubator was successfully implemented in 2016 in Khabarovsk on the territory of the Pacific State University. Project activities are continued and scaled. So, at the time of the project's implementation in 2019, the project involved 12 Russian Universities and 12 Chinese Universities, 146 residents from two countries who completed a full acceleration course and more than 1,500 volunteers who attended the educational part of the project.

The project provides an opportunity for young people to learn the perfect methods of building a business, gain new competencies in the field of entrepreneurial activity, increase their horizons through direct involvement in the educational program, and also begin cooperation with their colleagues from China.

The key priority of the Project, in the context of the development of human capital of the Kemerovo region, is the opportunity to master leadership, team and management skills. Mastering soft skills by active entrepreneurs allows solving several problems for the economy of the Kemerovo region.

So in the industrial sector of the economy of the Kemerovo region, the project allows you to create a pool of managers who are able to modernize and develop advanced technologies for the development of specific enterprises in the raw materials and manufacturing sectors. According to the Strategy for socio-economic development of the Kemerovo region until 2025 , currently $88 \%$ of the total exports of the Kemerovo region is raw materials, $50.3 \%$ of the import structure is industrial equipment. Along with this, there are potential conditions for the development of domestic engineering in the formation of a cluster on the basis of existing enterprises, but this takes time, and an order for a qualitatively new equipment will be already formed in the coming years. During this time, the industrial enterprises of the region must undergo a radical technological modernization, as well as new mining complexes are designed and built.

Another important and actively developing area of activity of the modern economy of the Kemerovo region is tourism. Tourism plays an important role in solving the social problems of the Kemerovo region, ensuring the development of small business in small cities, regions 
and single-industry towns. Being an aggregate type industry, tourism has a stimulating effect on the development of related industries. In addition, the development of tourism contributes to the development of international and inter-regional cooperation, increases the cultural level of the population, the level of patriotism and self-identification of residents of the Kemerovo region. Currently, tourism in the Kemerovo region shows high growth dynamics, while reserves for growth have not been exhausted, and the achieved volumes can be increased more than 2 times in the period until 2025.

One of the most important and at the same time not typical for the Kemerovo region directions is agriculture, in particular, this direction includes the manufacture of craft products of farm production, as well as the collection and preparation of wild plants. The organization of this entrepreneurial activity requires extraordinary skills of managers, especially at the time of scaling and maintaining product quality control.

A comprehensive study of the activities of innovative start-ups at the time of their acceleration in the "Russian-Chinese Youth Business Incubator" project and isolating the results of the Project in the Kemerovo region shows the effectiveness of the applied acceleration technologies, which is actual confirmation of the effectiveness of the chosen strategy for the development of human capital in the Kemerovo region.

Table 1. KPI of Russian-Chinese Youth Business Incubator.

\begin{tabular}{|l|c|c|c|c|}
\hline & $\begin{array}{c}\text { Russia } \\
\mathbf{2 0 1 8}\end{array}$ & $\begin{array}{c}\text { Kemerovo } \\
\text { region 2018 }\end{array}$ & $\begin{array}{c}\text { Russia } \\
\mathbf{2 0 1 9}\end{array}$ & $\begin{array}{c}\text { Kemerovo } \\
\text { region 2019 }\end{array}$ \\
\hline Federal budget financing & 26.5 & 2.5 & 35 & 2.3 \\
\hline Regional budget financing & 1.4 & 1 & 2 & 1 \\
\hline Investing contracts mln. rub & 1370 & 240 & 2466 & 535 \\
\hline $\begin{array}{l}\text { Number of investing } \\
\text { contracts }\end{array}$ & 14 & 2 & 18 & 5 \\
\hline Cities & 10 & 1 & 12 & 1 \\
\hline Russian residents & 100 & 10 & 180 & 15 \\
\hline $\begin{array}{l}\text { Investing contracts, rub, / } \\
\text { Federal and Regional } \\
\text { funding }\end{array}$ & 49 & 69 & 67 & 162 \\
\hline $\begin{array}{l}\text { Investing contracts to } \\
\text { residents ratio }\end{array}$ & $14 \%$ & $20 \%$ & $10 \%$ & $33 \%$ \\
\hline
\end{tabular}

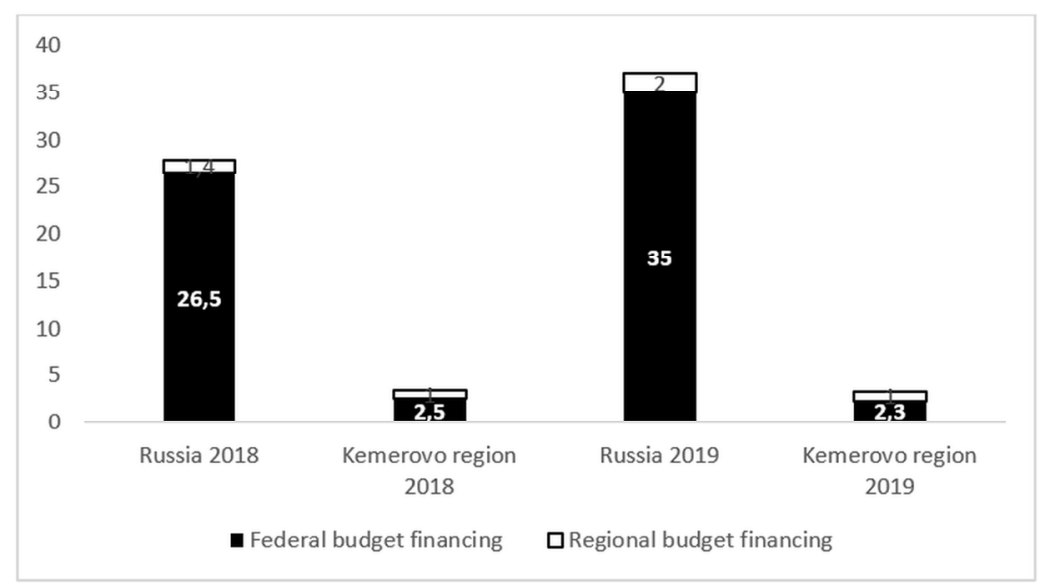

Fig. 1. State funding in Russian-Chinese Youth Business Incubator. 


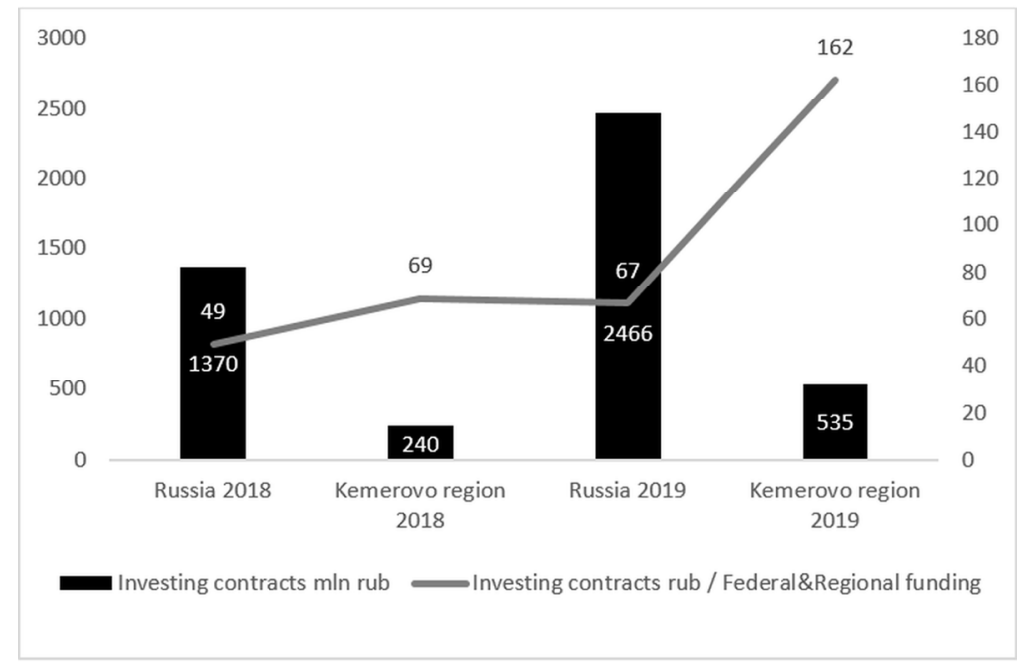

Fig. 2. Efficiency of state funding in Russian-Chinese Youth Business Incubator.

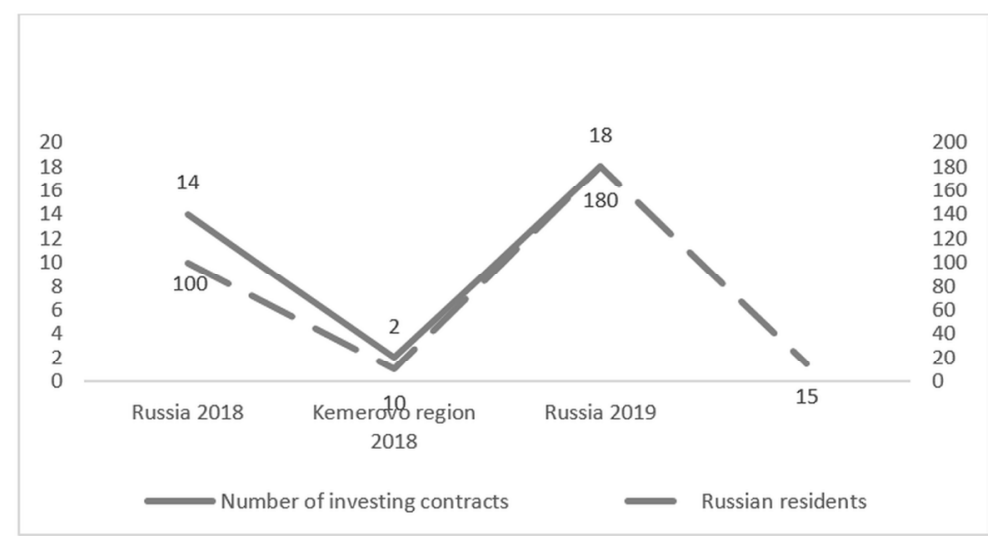

Fig. 3. Residents to investment contract ratio.

International experience shows that most high-tech startups are organized by energetic young students and university staff who leave the academic environment to found a company, or by people still associated with research activities in order to use new ideas and knowledge developed at the head university. A good education, knowledge of the academic environment, and scientific work skills allow them to gain access to expensive research equipment to qualified personnel, as well as to find, comprehend and combine potentially valuable pieces of knowledge, thereby creating an innovative product.

At the same time, high-tech startups can be organized by independent young researchers, scientists and specialists with an active lifestyle and innovative thinking. Such a human resource - academic human capital (AHC), possessing a wide range of scientific knowledge, often does not have the organizational and managerial experience, the necessary professional skills for the successful commercialization of its ideas and developments. As a result of the activities of high-tech start-up companies, the "processing" of academic human capital takes place and its transformation into invaluable innovative human capital, including due to the absorption of new experience, knowledge and skills during the implementation of joint foreign innovation projects. 
Thus, it seems possible to say that, in addition to the commercialization of technologies, one more important role of the Russian-Chinese Youth Business Incubator Project in the economy of the Kemerovo Region is revealed, namely, the reproduction of human capital.

In foreign practice, there are many fruitful examples of cooperation between business structures and institutions of higher education. For example, at the University of Manchester Institute of Science and Technology (The University of Manchester Institute of Science and Technology) in the UK, the Northern Aerospace Technology Research Center was created. Or the University of Lancaster, where the Union for the Environment is located, founded to promote science-intensive businesses in the field of environmental services and technologies. An example of continental European universities is also of interest. Interesting, in our opinion, is the experience of Aalto University (Aalto University) [1], Finland, which created the concept of individual business projects (Customized Business Projects [2]). These projects have enabled students to connect with various aspects of the business, such as marketing, finance, logistics and economics.

However, the project under consideration is focused not only on building an effective system of interaction between the university and entrepreneurial structures, as a kind of practical solution, which is the "Russian-Chinese Youth Business Incubator" program on the territory of higher educational institutions. But also on combining the scientific and technical base of the university and representatives of the professional community who have achieved practical results, mentors from the business environment, which in the first place allows to achieve a positive effect in creating a new generation of entrepreneurs developing the innovative sphere of production and provision of services, that is, the human capital of the region .

\section{Conclusion}

Summing up, we can state that in the modern economic system, one of the resource factors determining the intensity and quality of economic growth is human capital. Human capital is a stock of knowledge, professional experience, health, motivation, and other elements formed as a result of investments that brings a person income as a result of his effective use. The study of factors and conditions for the implementation of the policy of using human capital in the region opens up new opportunities for its improvement, including in terms of methodological approaches to its implementation.

\section{References}

1. Aalto University. URL: http://biz.aalto.fi/en/

2. Cooperation Projects of Aalto University. URL: http://biz.aalto.fi/en/cooperation/for corporations/projects/

3. G. Becker, Human Capital. A Theoretical and Empirical Analysis with Special Reference to Education (Columbia University Press, New York, 1964)

4. E. E. Shvakov, G. G. Vukovich, I. N. Shvetsova, Budget Limitations as a Barrier on the Path of State Management of Socioeconomic Development of a Multicultural Region (Springer Nature Switzerland AG, Berlin, 2020)

5. A. O. Hirshman, The Strategy of Economic Development (Yale University Press, New Haven, 1958)

6. W. Petty, Political Arithmetick (Hansebooks, London, 2018) 
7. 7. European Union Council, Report to the European Commission on new models of learning and teaching in higher education (Publications Office of the European Union, Luxembourg, 2014)

8. 8. S. Zhironkin, D. Khloptsov, N. Skrylnikova, I. Petinenko, O. Zhironkina, E3S Web Conf., 41, 04010 (2018)

9. 9. S. Zhironkin, S. Demchenko, G. Kayachev, M. Ryzhkova, O. Zhironkina, E3S Web Conf., 41, 04011 (2018)

10. 10. T. Snegireva, N. Kudrevatykh, A. Tselisheva, E3S Web Conf., 15, 04006 (2017) 